\title{
Leeuwen, Theo Van e Carey Jewitt (eds.) (2001) Handbook of Visual Analysis. London: Sage
}

Zara Pinto-Coelho

Ao longo dos anos as práticas comunicacionais quotidianas dos chamados países desenvolvidos têm vindo a mudar. Uma das manifestações desta mudança reside no uso crescente das imagens visuais em todos os domínios da vida social e cultural. Quando lemos jornais ou revistas, e até mesmo géneros textuais mais nobres, como sejam documentos produzidos por universidades, empresas e departamentos governamentais, raramente estamos conscientes desta tendência e do seu potencial retórico. Mas existe já uma abundante literatura nas ciências sociais e humanas que abre caminho para o desenvolvimento das competências necessárias a práticas de leitura mais atentas, e ao exame sistemático das práticas visuais que inundam a cultura contemporânea. Uma dessas obras é o manual de análise visual editado por Theo van Leeuwen e Carey Jewitt. Trata-se de uma introdução multidisciplinar a um amplo e diversificado leque de métodos de análise visual, contemporânea de uma série de obras sobre o assunto. Uma dessas obras é o livro Visual Methodologies, de Gillian Rose (2001). Ao contrário do que se verifica neste livro - em que a autora se apropria de algumas abordagens de análise visual e as apresenta ao leitor -, Theo van Leeuwen e Carey Jewitt dão voz a um conjunto de dez peritos (incluindo eles próprios) representantes de diferentes áreas de investigação dos estudos visuais. São elas: análise de conteúdo, antropologia visual, estudos culturais, iconografia, psicanálise, semiótica social, etnometodologia e teoria do cinema. Cada um dos oito capítulos, escrito por um desses peritos, introduz-nos de forma clara, informativa e pedagógica na teoria e na aplicação dos respectivos métodos e apresenta estudos de caso elucidativos. O que torna ainda mais interessante e profícua esta escolha é o facto de estes capítulos não serem estanques. Por um lado, porque são os próprios autores que fazem remissões para outros capítulos. Por outro, e esta será talvez a novidade maior, porque vários autores incluem nas suas análises recursos retirados das outras perspectivas, constituindo assim exemplos evidentes da multidisciplinaridade em acção. Refiro-me aos capítulos 2 (Bell), 5 (Van Leeuwen), 7 (Jewitt e Oyama), 8 (Goodwin) e 9 (Iedema) e às propostas de combinação entre análise de conteúdo e análise semiótica social, semiótica e iconografia, semiótica social e etnometodologia, e teoria do cinema e semiótica social, respectivamente. Para além da intertextualidade e do diálogo interno, há outro factor que contribui para a coerência da obra: todos os capítulos seguem uma estrutura semelhante. Antes de passarem à análise do caso ou casos, os autores introduzem o leitor nas definições teóricas do 
campo e rematam com um balanço centrado no(s) método(s) em causa, nos seus limites e na sua validade, e nas suas diferenças e semelhanças.

No segundo capítulo, Phillipe Bell, conhecido pelo seu vasto trabalho sobre a linguagem e o discurso da imprensa diária escrita, centra-se na análise de conteúdo, mostrando - através do exemplo da capa da revista feminina Cleo - como é que este método que sabemos quantitativo se pode articular com métodos qualitativos. Passo a passo, Bell mostra como proceder numa análise deste tipo, indicando e explicando os aspectos a ter em conta (definição de variáveis, dos seus valores e respectiva quantificação), e os cuidados de objectividade e de consistência que enformam a classificação de dados visuais. Trata-se de um exercício nem sempre fácil de acompanhar, pelo menos para os leitores menos familiarizados com a análise quantitativa. No entanto, especialmente para aqueles cuja leituras sobre a análise de conteúdo se esgotam na obra de Laurence Bardin (s/d), este capítulo de Bell sobre a possibilidade de estender a quantificação ao visual abre com certeza novos caminhos. Mas, como defende o autor, não nos devemos deixar fascinar ou limitar por esta possibilidade: qualquer análise de conteúdo de textos visuais deve "suplementar e estender os seus resultados através de uma análise detalhada de exemplos típicos" (p. 34). Este é um exercício que o autor propõe aqui apenas em termos de hipótese, mas que vai continuar em trabalhos posteriores (Bell, 2002).

Collier, no capítulo 3, concentra-se na fotografia, e dada a sua formação de antropólogo, chama-nos a atenção para um aspecto fundamental na compreensão do visual: a necessidade de levar em conta o contexto, de procurar informação contextual que torne a imagem ou imagens analiticamente inteligíveis. Apesar de o título deste texto apontar para a pluralidade ("Abordagens à análise na antropologia visual”), o que encontramos aqui descrito é apenas a abordagem de Collier, uma abordagem baseada nos princípios do realismo visual e centrada no "estudo da comunidade". No entanto, este capítulo torna-se particularmente interessante pelo conjunto de recomendações que nele podemos encontrar para tornar a prática da investigação visual mais fácil e produtiva. Collier tem o cuidado de incluir dicas muito concretas que raramente encontramos em livros de métodos, e fá-lo de uma forma muito original e prosaica. Para este investigador "devemos brincar com as imagens até que elas falem connosco directamente, e é desse diálogo que tiramos os nossos resultados” (p. 59).

No capítulo 4 Martin Lister e Liz Wells apresentam uma introdução compreensiva, historicamente informada e interdisciplinar aos estudos culturais como uma análise do visual que "permitem ao analista levar em conta os muitos momentos que integram o ciclo de produção, circulação e consumo da imagem através dos quais os significados se acumulam, escorregam e mudam" (p. 90). Este capítulo - central no livro - fornece não só um sumário exaustivo das abordagens ao visual dos estudos culturais, como constitui também, no contexto desta colectânea multidisciplinar, um ponto de referência que enforma o uso dos métodos descritos nos outros capítulos. Contrariamente ao que defende Collier, Lister e Wells argumentam que as fotografias são "artefactos culturais codificados de forma complexa, e não "uma fonte de factos objectivos e desinte- 
ressados” (p. 89), um argumento que é ilustrado pela análise de um conjunto diverso de fotografias. No global, diríamos que os autores são bem sucedidos nesta tarefa.

O tema de que se ocupa Theo van Leeuwen no capítulo 5 é a semiótica visual de Roland Barthes e a iconografia. Segundo o autor, as principais diferenças entre os métodos residem em primeiro lugar nos objectos de estudo respectivos: obras de arte do passado versus as imagens mediáticas do presente. Outra diferença é que a semiótica visual de Barthes se centra na imagem em si e trata os significados culturais como um dado adquirido, enquanto a iconografia também usa argumentos baseados na comparação intertextual e na investigação de arquivo, prestando atenção ao contexto em que a imagem é produzida e posta a circular, e aos "comos" e "porquês" do surgimento histórico dos significados culturais e das suas expressões (p. 94). Contudo, van Leeuwen mostra no seu artigo, através de exemplos concretos, como é que a iconografia também pode ser aplicada na análise de imagens contemporâneas.

No capítulo 6, Gertraud Diem-Wille recorre a estudos de casos para demonstrar o valor do uso dos desenhos infantis em projectos de investigação na área da psicanálise e das ciências sociais. Como expressões “de desejos inconscientes e de conflitos” (p. 132), esses desenhos podem complementar a informação fornecida por entrevistas em projectos desenvolvidos na área das ciências sociais, embora, como ela própria o reconhece, tal tarefa exija que o entrevistador esteja familiarizado com a teoria psicanalítica.

A forma como a semiótica social aborda a comunicação visual é o tópico de que nos falam Carey Jewitt (uma das editoras deste livro) e Rumiko Oyama no capítulo 7. Para ilustrar esta abordagem, os autores recorrem a várias imagens de um estudo sobre a representação visual da heterossexualidade masculina em materiais de saúde sexual britânicos dirigidos a pessoas entre os 13 e os 19 anos de idade. Embora os autores descrevam e expliquem com algum detalhe os principais recursos que a semiótica social dispõe para explorar a imagem, a complexidade original desta abordagem não facilita a sua compreensão, facto que é reconhecido pelos próprios autores. Contudo, Jewitt e Oyama chamam a atenção para um aspecto fundamental: a ideia de que a semiótica social visual só por si não é suficiente. Desenganem-se, portanto, os que a pensam como "receita". Se é verdade que esta abordagem pode revelar coisas que não são evidentes à primeira vista, também é certo que o seu potencial se revela apenas numa equação interdisciplinar que envolva teorias sociais relevantes para o estudo em causa, e outras metodologias que permitam uma análise mais sistemática e comparada de conjuntos de imagens (p. 154). Só desta forma esta abordagem poderá conseguir atingir o fim último a que se propõe: “ajudar a melhorar e mudar as práticas (como a produção de brochuras informativas, ou o ensino), que pode depois levar (...) ao desenvolvimento de recursos semióticos novos e a um uso diferente dos recursos existentes” (p. 155).

Charles Goodwin discute no capítulo 7 o papel de um leque de diferentes tipos de imagem no trabalho dos cientistas e de outros peritos. Neste caso, o da análise conversacional e da etnometodologia, a análise visual não se ocupa tanto da imagens, mas antes da análise do desenrolar dinâmico de práticas comunicativas onde as imagens e 
outros signos não verbais (e.g., olhar, orientação do corpo, gestos) desempenham um papel. Goodwin centra-se na forma como as imagens são construídas, vistas e usadas pelos participantes num ambiente específico, e usa para ilustrar a sua argumentação diferentes tipos de exemplos (e.g., conversas, práticas científicas, policiais). Este capítulo constitui um bom exemplo a favor da necessidade de a análise visual integrar nas suas preocupações a análise das práticas discursivas - aqui definidas como "as práticas mais gerais usadas para construir a acção no interior da interacção humana situada" (p.179) - e evitar assim uma excessiva particularização e atomização que pode levar a um foco redutor na imagem visual como objecto e produto.

O capítulo 9 explora a possibilidade de combinar conceitos da teoria do cinema com a semiótica social na análise de telefilmes, usando como exemplo um documentário sobre um hospital. Rick Iedema mostra que uma análise sócio-semiótica dos traços visuais, linguísticos e sonoros pode revelar como é que neste tipo de filme são construídos e reforçados os "efeitos de verdade" de pontos de vista particulares, neste caso concreto, de uma minoria profissional.

A diversidade de abordagens e disciplinas reunidas neste manual, assim como a exemplificação do seu funcionamento, constituem sem dúvida pontos fortes desta obra. Dá aos principiantes a possibilidade de ficarem com uma ideia geral da diversidade de métodos existentes, ao mesmo tempo que alarga os horizontes dos estudiosos ou investigadores do visual. No entanto, como é facilmente compreensível, o risco da simplificação é enorme. A complexidade dos quadros teóricos e metodológicos das abordagens discutidas não é compatível com o magro espaço a que têm direito. Apesar de tudo, parece-nos que o esforço dos editores foi bem sucedido: o de produzirem um livro que dá um conjunto de escolhas passíveis de serem usadas na "investigação da representação visual de assuntos sociais significantes" (p. 1). O último aspecto a salientar é o facto de os editores não tomarem como sua a prerrogativa de "construir argumentos teóricos a favor da ideia da imagem como construção ou como realidade" (p. 5). Preferem antes chamar a atenção para esta distinção, ao mesmo tempo que mostram como é que em projectos de investigação específicos se tem de fazer uso da diversidade para dar resposta ao pretendido. Esta flexibilidade e abertura disciplinar são para mim uma das riquezas desta obra. Só este modelo democrático de multivocalidade disciplinar poderá permitir avançar no conhecimento e na compreensão do mundo visual à nossa volta. Como dizem os editores, a análise visual permanece uma arte de interpretação, mas deve assentar numa análise detalhada e sistemática. A obra recenseada ilustra a abertura que deve fazer parte dessa arte e desse saber.

\section{Referências bibliográficas}

Bardin, Laurence (s/d) Análise de Conteúdo. Lisboa: Ed. 70.

Bell, Allan (2002) “Goffman's Gender Advertisements revisited: Combining content analysis with semiotic analysis" in Visual Communication, 1, 2, 203-222.

Rose, Gillian (2001) Visual Methodologies. London: Sage. 